\title{
REIGNY, Dossier documentaire (1369-1371)
}

Description des destructions opérées par les grandes compagnies dans l'abbaye de Reigny à travers un dossier documentaire (1369-1371)

\section{Marlène Hélias-Baron}

\section{(2) OpenEdition}

Journals

Édition électronique

URL : https://journals.openedition.org/cem/5462

DOI : $10.4000 /$ cem. 5462

ISSN : 1954-3093

Éditeur

Centre d'études médiévales Saint-Germain d'Auxerre

Référence électronique

Marlène Hélias-Baron, «REIGNY, Dossier documentaire (1369-1371) », Bulletin du centre d'études médiévales d'Auxerre I BUCEMA [En ligne], Collection CBMA, mis en ligne le 25 mars 2008, consulté le 24 septembre 2022. URL : http://journals.openedition.org/cem/5462 ; DOI : https://doi.org/10.4000/ cem.5462

Ce document a été généré automatiquement le 24 septembre 2022.

\section{c)}

Creative Commons - Attribution - Pas d'Utilisation Commerciale - Partage dans les Mêmes Conditions 4.0 International - CC BY-NC-SA 4.0

https://creativecommons.org/licenses/by-nc-sa/4.0/ 


\section{REIGNY, Dossier documentaire (1369-1371)}

Description des destructions opérées par les grandes compagnies dans l'abbaye de Reigny à travers un dossier documentaire (1369-1371)

\section{Marlène Hélias-Baron}

1 La période de la Guerre de Cent ans a été l'occasion pour toutes sortes de brigands de piller ou simplement rançonner villes, villages et monastères isolés ${ }^{1}$. Au milieu du XIV ${ }^{e}$ siècle, les Grandes compagnies ont traversé le royaume de France et les régions avoisinantes en ravageant tout ou presque sur leur passage. Parmi toutes les autres, la région d'Auxerre a connu elle-aussi ce fléau. En effet, dans les années 1360, une bande d'Anglais et de Bretons s'est installée à Arcy-sur-Cure et en a profité pour piller les environs; l'abbaye cistercienne de Reigny, située sur la Cure, entre Vermenton et Vézelay, n'a pas été épargnée ${ }^{2}$. Pour éviter que les moines ne se retrouvent dans une telle situation, le comte d'Auxerre leur avait pourtant donné en 1355 l'autorisation de creuser un fossé devant la porte de leur abbaye et d'y mettre un pont-levis pour se protéger des attaques éventuelles ${ }^{3}$. Ce comte était coutumier du fait, puisqu'il accorda au village de Chitry la permission de fortifier l'église paroissiale en $1364^{4}$. Son action n'est pas isolée : les pouvoirs publics ont en effet encouragé ou provoqué la mise en défense des villages et des monastères ${ }^{5}$. Cela n'a pas suffi puisque l'abbaye de Reigny et sa grange ont été attaquées. Après le départ des pilleurs, les moines blancs ont été dans l'obligation de faire le compte des dégâts et de penser à reconstruire les bâtiments incendiés. À ce sujet, leur chartrier contient un intéressant dossier composé de trois actes livrant une description pathétique des dommages subis et cherchant les moyens d'y mettre bon ordre ${ }^{6}$. Les documents qui nous intéressent ici ont été délivrés entre 1369 et 1371, soit au moment d'une accalmie dans le conflit franco-anglais ${ }^{7}$.

Composition du dossier : une charte de supplication, un rapport d'inspection et une charte d'autorisation

2 Tout commence avec une charte datée de septembre 1369 adressée à l'abbé de Cîteaux, aux autres abbés cisterciens qui doivent se rendre à un futur Chapitre général, dont la date n'est pas fixée, ainsi qu'aux définiteurs ${ }^{8}$. Les auteurs en sont l'abbé de Reigny, le 
prieur, le portier, le sacristain, le procurateur, le cellérier et cinq autres moines, tous prêtres, c'est-à-dire la major vel sanior pars du monastère de Reigny ${ }^{9}$. Ces hommes décrivent une situation catastrophique : l'abbaye et ses environs ont été dévastés, le bétail pris ou tué, la grange abbatiale incendiée. Devant ce désastre, les moines ont fui avec leurs biens. Cependant, tout ce qu'ils ont emporté avec eux à Vermenton a été saisi après la prise de la ville par les hommes d'armes, l'abbé devant même payer une substantielle rançon pour sa libération ${ }^{10}$. Ils se retrouvent dans une situation si critique qu'ils sont dans l'obligation de demander tous ensemble aux abbés cisterciens la permission d'aliéner une partie de leurs biens pour restaurer les bâtiments endommagés ${ }^{11}$. Ils sollicitent en fait le droit de pratiquer une coupe de cent arpents dans les bois de Tréclin pour la vendre et financer à la fois les réparations et le remboursement des dettes contractées auprès de seigneurs et autres personnes compatissantes qui leur avaient prêté du blé, du vin et de l'argent pour les soutenir quelques temps.

3 Quelques mois plus tard, un rapport d'inspection destiné à un futur Chapitre général fut établi par les abbés de Quincy et des Écharlis ${ }^{12}$. Ces deux hommes ont été envoyés par les définiteurs nommés lors du dernier chapitre général, chacun ayant été mandaté par un ou deux abbés en particulier ${ }^{13}$. Pourvus de lettres de mission, ils se sont rendus sur place pour examiner la validité d'une supplique envoyée par les moines de Reigny à Cîteaux ${ }^{14}$. En présence de Guillaume, clerc et notaire public, ils ont réuni dans la salle du chapitre l'abbé et la majorque at sanior pars totius conventus ejusdem monasterii. Une fois rassemblés, les moines de Reigny ont juré de la véracité de leurs propos contenus dans la supplique. Les deux délégués ont regardé dans le même temps avec attention un document authentique marqué du seing et de la souscription du notaire Guillaume, scellé des sceaux de l'abbé et du convent de Reigny, c'est-à-dire la charte précédente délivrée en $1369^{15}$. Ainsi, devant le texte de ce rapport, on peut penser que deux documents ont circulé entre Reigny et les définiteurs : une simple supplique et une charte en bonne et due forme que les délégués ont examinée une fois arrivés à Reigny à moins que les deux écrits (supplique et charte) ne soient confondus ${ }^{16}$. Finalement, devant les informations recueillies, les deux abbés reconnaissent que la demande des moines de Reigny est recevable : ils peuvent procéder à la coupe puis à la vente du bois de Tréclin pour restaurer leurs bâtiments et régler leurs dettes, le notaire servant de témoin et de caution ${ }^{17}$. Toute la difficulté est que les statuts du Chapitre général ne conservent aucune trace de cette affaire et des actes auxquels elle a donné lieu. Pourquoi? Une ébauche d'explication est fournie par les statuts de 1389: les assemblées n'ont pas été réunies de manière régulière pendant de nombreuses années à cause des désordres enfantés par la guerre. D'ailleurs, les deux documents de 1369 et 1370 sont adressés aux définiteurs et aux abbés cisterciens qui doivent se réunir prochainement, mais pas aux abbés réunis en Chapitre général ${ }^{18}$.

Le 12 mai 1371 enfin, dans la salle capitulaire de Reigny, après avoir lu le rapport des abbés des Écharlis et de Quincy, les abbés de Clairvaux et de Fontenay, commissaires plénipotentiaires du Chapitre général, ont confirmé - par l'autorité du susdit chapitre l'autorisation de procéder à la coupe de bois à condition que l'argent obtenu ne serve qu'aux réparations et au paiement des dettes ${ }^{19}$. Le nouvel acte est attaché au rapport de 1370 par des lanières de parchemin, au niveau du repli. Les deux abbés y apposent finalement leur sceau. 
5 Ainsi, la simple volonté de procéder à une vente de bois pour obtenir de l'argent frais a conduit les moines de Reigny à solliciter le Chapitre général ${ }^{20}$. Pour régler cette affaire, au moins trois écrits ont été produits : la demande, l'examen de la demande et enfin l'autorisation. Les Cisterciens ont des habitudes bureaucratiques bien ancrées à la fin $\mathrm{du} \mathrm{XIV}^{\mathrm{e}}$ siècle! Pour confirmer et donner une plus grande validité aux documents ( $\mathrm{ad}$ majorem rei certitudinem), ils ont fait appel à un notaire public, nommé par l'évêque d'Auxerre, Guillaume le Grand ${ }^{21}$. Le recours à ce genre de personne ne se faisait jamais gratuitement, même si la somme versée n'est pas indiquée ${ }^{22}$.

Les actes dans tous leurs états : intervention d'un notaire et d'un moine

6 Outre leur intérêt historique indéniable, ces trois actes successifs présentent un intérêt paléographique et diplomatique considérable.

De la charte de supplication de 1369 au rapport d'inspection de 1370

7 Les deux documents de 1369 et de 1370 ont de nombreuses caractéristiques communes. Écrits sur de grandes feuilles de parchemin, ils ont d'abord un format similaire: ils sont tous les deux presque carrés. Le premier compte quarante-huit lignes justifiées à gauche, comme à droite, relativement serrées; le second est recouvert de trente-sept lignes espacées de $1 \mathrm{~cm}^{23}$. Tous les deux se terminent par un court paragraphe de sept à huit lignes, décalé à droite par rapport au reste du texte et séparé par un espace laissé vide de 1 ou $2 \mathrm{~cm}$. À gauche de ce paragraphe, dans l'alignement, se trouve à chaque fois une belle marque notariale.

8 À première vue, leurs écritures semblent voisines, même si une analyse paléographique s'avère nécessaire pour déterminer si un unique scribe s'est chargé - ou non - de leur rédaction. D'abord, il n'y apparaît aucune particularité graphique remarquable, sauf une initiale « $\mathrm{R}$ » plus grande que le reste des lettres. À cette exception près, l'écriture est uniforme sur les deux actes. L'encre utilisée est de couleur ocre, un peu effacée par endroits, ce qui rend la lecture un peu difficile.

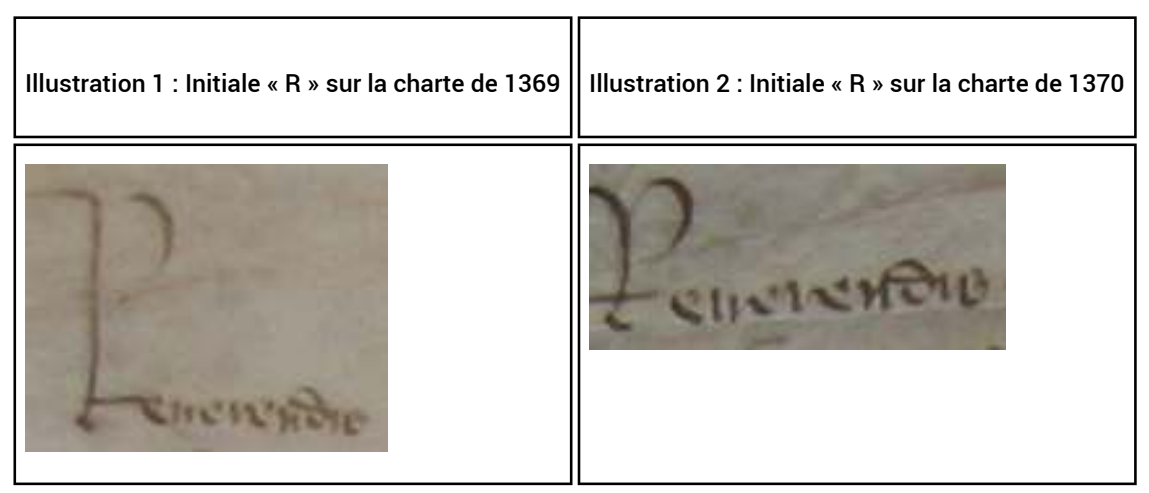

9 Sur chacun des deux actes, quatre lettres ont été sélectionnées pour servir de points de repère $: \mathrm{A}, \mathrm{d}$, $\mathrm{g}$ et $\mathrm{p}$, ainsi que trois abréviations (per, super et capitulo) et une expression (monasterii Cistercii).

Illustration 3 : Lettres issues de la charte de 1369 


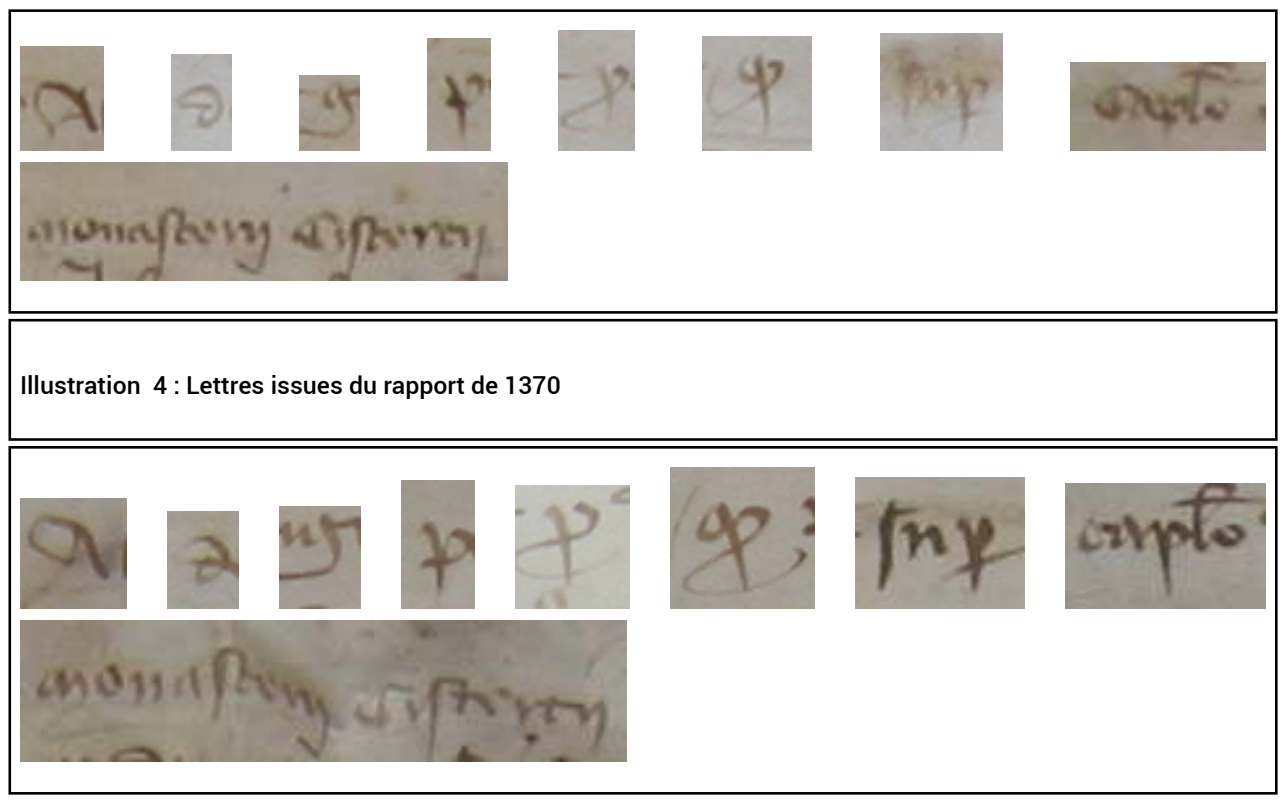

10 À l'observation, la manière de tracer les lettres est identique sur les deux documents. Les différences qui apparaissent sont liées au fait que l'écriture de la première charte est plus serrée que celle du rapport et que l'encre utilisée est plus claire ou plus passée. Sur une phrase complète, les ressemblances sont encore plus visibles. Au début du dernier paragraphe, se trouve la titulature du notaire : Et ego Guillelmus Grandi de Lano Autisiodorensis diocesis clericus... La main qui a tracé ces mots est la même : les lettres et les abréviations sont identiques ainsi que la place occupée sur le parchemin.

Illustration 5 : Écriture sur la charte de 1369

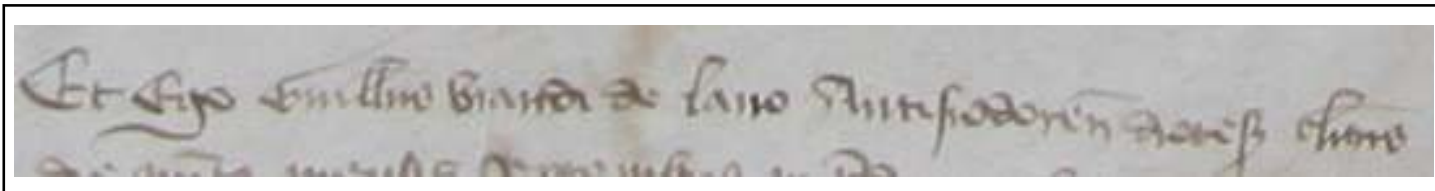

Illustration 6 : Écriture du rapport d'inspection de 1370

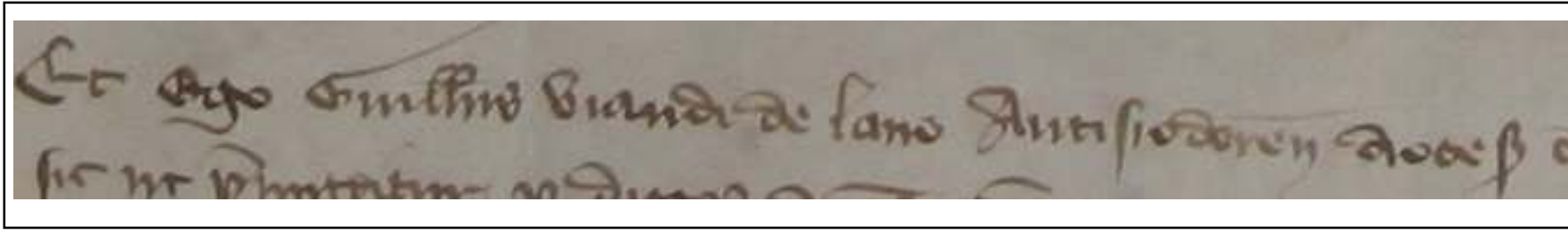

11 À partir de cette analyse paléographique, le copiste peut-il être identifié ? S'agit-il du notaire public déjà mentionné, à savoir Guillaume le Grand de Lano ? Sachant que les notaires sont généralement les rédacteurs des actes qui leur ont été commandés, même s'ils peuvent laisser le travail d'écriture à un autre scribe et se contenter d'apposer leur seing manuel sur le document, il ne serait pas surprenant que Guillaume se soit chargé 
personnellement de la besogne, d'autant qu'il l'affirme dans la mention hors teneur du rapport de $1370^{24}$.

Outre ces similitudes formelles et graphiques, des ressemblances se manifestent entre les deux textes : le rapport s'inspire de la charte de supplication. Les abbés délégués l'ont en effet regardée et ont répété de nombreuses expressions utilisées quelques mois auparavant, surtout dans l'adresse aux abbés cisterciens. Ces reprises sont dues au fait que c'est le même scribe qui a rédigé le nouvel acte et qu'il a très probablement utilisé des formules préétablies, probablement copiées dans un formulaire ou mieux un Ars notarie $e^{25}$. Cela est particulièrement visible dans la mention hors-teneur, à savoir la confirmation notariale ${ }^{26}$. L'hypothèse se confirme quand cette phrase se retrouve à quelques variantes près dans un vidimus de Reigny daté de 1369 et copié dans le cartulaire $^{27}$.

Dernières similitudes, externes cette fois-ci. Les deux documents ont pour caractéristique d'être pourvus de deux signes de validation différents ${ }^{28}$. D'abord, ils étaient tous deux scellés, même si les sceaux ont à présent disparu : il ne reste que des lanières de parchemin pendant au bas des feuilles. Selon les eschatocoles, ces sceaux étaient ceux de l'abbé et du convent de Reigny pour la charte de 1369 et ceux des deux abbés des Écharlis et de Quincy pour le rapport de 1370. Les sceaux abbatiaux, selon une décision prise par le Chapitre général de 1200, devaient représenter l'abbé en pied avec une crosse dans la main droite et un livre - la Règle - dans l'autre avec une devise anonyme écrite autour de l'image ${ }^{29}$.

14 Autre signe de validation, encore présent : le seing manuel dessiné par le notaire luimême. L'annonce de son apposition est faite dans les deux eschatocoles; sa présence est considérée comme indispensable à la validité et à l'authenticité du document ${ }^{30}$. Sur les deux actes, le seing est identique : il s'agit d'un dessin géométrique dont la partie supérieure ressemble à une étoile portée par une colonne et la partie inférieure à un piédestal.

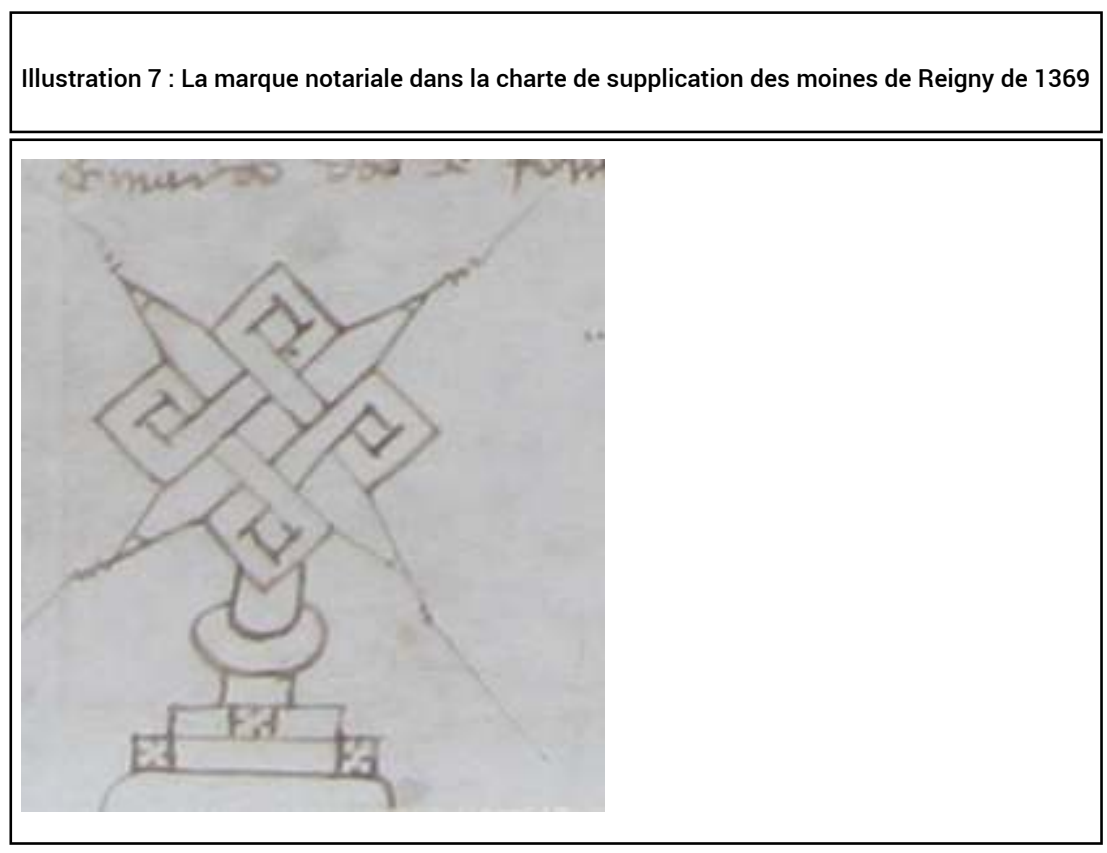


Illustration 8 : Marque notariale sur le rapport d'inspection de 1370

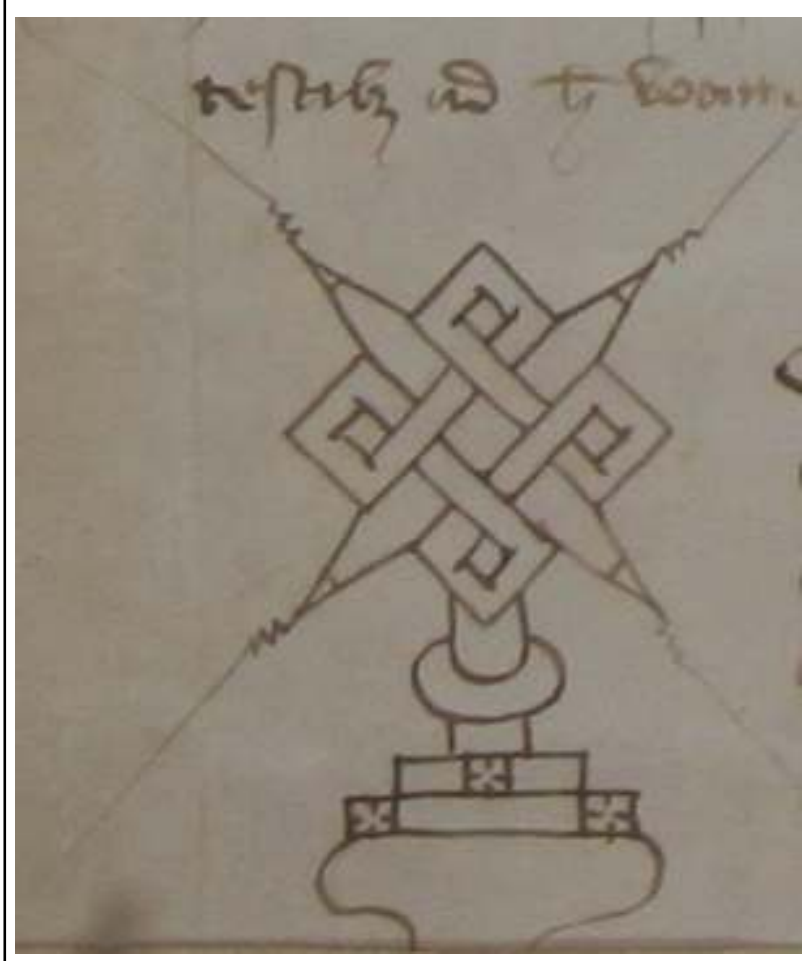

En conclusion: les deux actes de 1369 et 1370 sont deux belles chartes notariales, pourvues de tous les signes de validation attendus pour ce genre de document, même si les sceaux ont été égarés. Les moines de Reigny, comme tous les autres Cisterciens, sont prudents: ils veulent que l'autorisation reçue soit pourvue des meilleures garanties possibles!

Un document joint : l'autorisation définitive de procéder à la coupe de bois

Le dossier se clôt sur un dernier témoin, de plus petite taille que les autres : il mesure $12,5 \mathrm{~cm}$ de haut pour $19 \mathrm{~cm}$ de large. C'est une feuille allongée, dont le parchemin est très fin, déchiré en haut sur le côté droit. Il compte 16 lignes réglées à la pointe sèche. L'écriture est de petit format et ne ressemble pas à celle du notaire Guillaume. Ce document a peut-être été rédigé par un moine de Reigny ou un scribe de l'entourage des deux abbés. Ce document fixé au rapport par des lanières de parchemin est une simple autorisation complémentaire, même si les religieux l'ont jugé suffisamment important pour être conservé avec les deux autres actes de la série.

Les ravages de la guerre de cent ans ont poussé les moines de Reigny à solliciter l'autorisation du Chapitre général pour procéder à une aliénation d'une partie de leur patrimoine. L'affaire a fait couler beaucoup d'encre et a nécessité l'emploi de beaucoup de parchemin : la demande en elle-même, un rapport d'inspection et une autorisation finale. Malgré toutes les précautions prises pour relever le patrimoine, les difficultés des Cisterciens ne sont pas terminées et leurs risques d'être pillés subsistent, au point qu'en 1378 le roi Charles V leur a délivré un diplôme qui leur donnait le droit de se réfugier à Vermenton en cas de problème ${ }^{31}$. Ce service n'est pas gratuit puisque les 
moines ont dû contribuer à la réparation des remparts et ont dû faire construire à leurs frais à l'intérieur de l'enceinte une maison pour s'y réfugier.

\section{NOTES}

1. Jean FAVIER, La guerre de cent ans, Paris, 1980, p. 265, 307 et 309. David N. BELL, « Les Echarlis », in Les Cisterciens dans l'Yonne, Pontigny, 1999, p. 139. Denis CAILLEAUX, « Vauluisant », in Les Cisterciens dans l'Yonne, Pontigny, 1999, p. 103. Olivier WEETS, « Le site de l'abbaye de Morimond : état des connaissances historiques et archéologiques », in Morimond. Cahiers Haut-marnais, 196-199, 1994, p. 163.

2. Henri DENIFLE, La désolation des Églises, Monastères et Hôpitaux en France pendant la guerre de Cent Ans, t. I : La guerre de cent ans jusqu'à la mort de Charles V, Paris, 1899 (Impression anastaltique, Bruxelles, 1965), p. 471 et 472. Nathalie CÊTRE, Étude architecturale de l'abbaye cistercienne de Reigny, Yonne, Mémoire de Maîtrise de l'Université de Bourgogne, 1997, p. 13 et 22. Charles PORÉE, « Les bâtiments de l'abbaye de Reigny et la vie monastique chez les Cisterciens », Bulletin des Sociétés savantes de l'Yonne, 1920, p. 6-7. 3. Paris, BnF, ms. lat. 17725, acte 10, fol. 6v : « Nous Jehan de Chalon, come Daucerre, sire de Roichefort et Bouteillier de France, savoir faisons que comme pour cause de plusieurs inconvénients, violences et domaiges de jour en jour dont faiz a noz biens amez les religieux abbe et convent de Reigny [...] suppliant sur ce [...] que de grace especial leur [...] octroier que devant la porte de leurdicte abbaye si comme len va a Vermenton il [...] faire faire ung bon fosse et ung pont leveys. Nous [...] considérant que sommes tenuz de leur donner aide comme leur gardien, voulons et nous plaist [...] que ledict fosse et pont leveys, il puissent faire faire, si comme il verront quil leur sera plus profitable. [...] Donneez en nostre hostel a Paris, le dernier jour du mois de juillet lan de Grace 1355 ».

4. Philippe contamine, "L'impact de la guerre de cent ans en France sur le " plat pays » et sur la vie au village ", in Les villageois face à la guerre (XIV ${ }^{e}-X V I I I^{e}$ siècle). Actes des XXII Journées Internationales d'Histoire de l'abbaye de Flaran 8, 9, 10 septembre 2000, Toulouse, 2002 , p. 31.

5. Gérard GIULIATO, «Insécurité et mise en défense du village en Lorraine médiévale », in Les villageois face à la guerre (XIV ${ }^{e}-X V I I I^{e}$ siècle). Actes des XXII Journées Internationales d'Histoire de l'abbaye de Flaran 8, 9, 10 septembre 2000, Toulouse, 2002, p. 36-45. Jean-Louis $\mathrm{ROCH}$, « Les guerres du peuple: autodéfense, révolte et pillage dans la guerre de Cent Ans ", in Images de la guerre de Cent Ans, D. Couty, J. Maurice, M. Gueret-Laferté (dir.), Actes du colloque de Rouen, Rouen, 2002, p. 47-61.

6. Denise ANGERS, « Le redressement difficile d'une capitale régionale après la guerre de Cent ans : Caen, 1450-1550 », in Philippe Contamine, T. Dutour, B. Schnerb (dir.),

Commerce, finances et sociétés (XI ${ }^{e}-X V I^{e}$ siècle). Recueil de travaux d'histoire médiévale offerts à Henri Dubois, Paris, 1993, p. 185-197 ; Claude GAUVARD, « Discipliner la violence dans le royaume de France aux XIV ${ }^{\mathrm{e}}$ et $\mathrm{XV}^{\mathrm{e}}$ siècles : une affaire d'État? ", in Disziplinierung im Alltag des Mittelalters und der frühen Neuzeit, Vienne, 1999, p. 173-204. 
7. A.D. Yonne, H 1570.

8. Jean-Berthold MAHN, L'ordre cistercien et son gouvernement des origines au milieu du XIII ${ }^{e}$ siècle, Paris, 1982, p. 190-193. Les définiteurs sont des abbés chargés de régler des affaires courantes et les querelles, qui prendraient trop de temps au Chapitre général, à cause du trop grand nombre de participants. Ils constituent « un tribunal suprême de l'ordre ».

9. A.D. Yonne, H 1570, acte de 1369 : ... humiles et devoti vestri frater Johannes humilis abbas monasterii Regniaci dicti Cisterciensis ordinis, Autissiodorensis diocesis, necnon fratres Petrus de Toiare prior ejusdem monasterii Regniaci, Laurentius portarius, Parisius sacrista, Dionysius de Viterello procurator, Philippus cellerarius, Johannes de Gillons vicesarius, Galterus de Dusei valle, Petrus de Autisodoro, Aymo de Poligniaco et Johannes de Crepo, omnes sacerdotes et monachi conventus dicti monasterii Regniaci, majorem et saniorem partem in duplo totius conventus predicti... : « ... vos humbles et dévots frère Jean, humble abbé du monastère de Reigny du dit ordre de Cîteaux, du diocèse d'Auxerre, et aussi les frères Pierre de Thouars, prieur du même monastère de Reigny, Laurent portier, Parisius sacristain, Denis de Viterelle procurateur, Philippe cellérier, Jean de Gillons vicesarius [?], Gautier de Douce vallée, Pierre d'Auxerre, Aimon de Poligny et Jean de Crepo, tous prêtres et moines du convent du dit monastère de Reigny, la plus grande et plus saine partie en double [?] de tout le susdit convent... ».

10. A.D. Yonne, H 1570, acte de 1369, lignes 9 à 14.

11. A.D. Yonne, H 1570, acte de 1369, lignes 23 à 24 .

12. A.D. Yonne, H 1570, acte de 1370.

13. ... humiles et devoti vestri fratres Guillelmus abbas humilis monasterii de Cuiniciaco ordinis predicti Lingonensis diocesis commissarius in hac parte a vobis dominis abbate Cistercii ceterisque diffinitoribus capituli generalis in Cistercii monasterio ultimo celebrati deputatus et frater Egidius humilis abbas monasterii de Eschalleys dicti ordinis Senonensis diocesis in hac parte deputatus a reverendo in Christo Patre ac domno domino abbate monasterii Clarevallis ordinis sepedicti, nosque de Cuiniciaco et de Eschalleys predictis monasteriorum predictorum abbates commissarii etiam in hac parte, deputati a reverendo in Christo patre ac domno domino abbate monasterii de Fonteneto ordinis predicti Eduensis diocesis, cocom $[\mathrm{m}]$ issarii nostri abbatis predicti de Cuiniciaco a vobis predictis dominis abbate Cistercii et aliis diffinitoribus specialiter deputati... : « ... vos humbles et dévots frères Guillaume, humble abbés du monastère de Quincy de l'ordre susdit, du diocèse de Langres, commissionné pour cette affaire par vous seigneurs abbé de Cîteaux et les autres définiteurs du chapitre général fait dernièrement dans le monastère de Cîteaux, et frère Egidius, humble abbé des Echarlis dudit ordre, du diocèse de Sens, député pour cette affaire par le révérend père et seigneur dans le Christ, l'abbé du monastère de Clairvaux du susdit ordre, nous abbés des monastères susdits de Quincy et des Echarlis commissionnés pour cette affaire par le révérend père et seigneur dans le Christ, l'abbé du monastère de Fontenay, de l'ordre susdit, du diocèse d'Autun, collègue de l'abbé susdit de Quincy, député par vous seigneurs abbés de Cîteaux et les autres définiteurs... ».

14. ... prout hec omnia constant per litteras commissionum predictarum nobis directarum de quibus vestris reverendis paternitatibus... ; ... in certa supplicacione pro parte religiosorum vestrorum abbatis et conventus monasterii Regniaci dicti ordinis Antissiodori diocesis in predicto capitulo ultimo celebrato facta de qua supplicatione in commissione predicta dicti capituli generalis habetur mentio specialis... 
15. ... de et super contentis tam in dicta commissione capituli generalis quam in dicta supplicatione et in quodam publico instrumento signo et suscriptione dicti publici notarii signato et subscripto ac sigillis dictorum abbatis et conventus Reigniaci, sigillato...

16. ... tam in dicto instrumento quam in dicta commissione capituli generalis fit mentio specialis et expressa...

17. Joseph CANIVEZ, Statuta capitulorum généralium ordinis cisterciensis ab anno 1116 ad annum 1786, t. III, 1935, 1369, 1370 et 1370, p. 548-552;1389, i, p. 558 : In primis guerrarum turbines, viarum discrimina et alia quamplurima tempestatum incommoda, quibus hodiernis diebus concutitur et comprimitur, proh dolor ! totus mundus, et obedientiae filii a suis sanctis propositis retardantur, considerans madentibus oculis Capitulum generale omnes et singulos abbates Ordinis, qui praesentes Capitulo debuerunt personaliter interesse, et nihilominus se super hoc excusantes tenet ipsum Capitulum a via praesentis Capituli favorabiliter excusatos. 18. A.D. Yonne, H 1570, actes de 1369 et de 1370 : Reverendis in Christo patribus et dominis nostris carissimis domino abbati monasterii Cistercii ejusque coabbatibus universis Cisterciensis ordinis et diffinitoribus in proximo generali capitulo Cisterciensi congregandis.

19. A.D. Yonne, H 1570, acte de 1371 : ... eisdem abbati et conventui suisque successoribus vendendi tonsuram dicte silve prout melius poterunt, concessimus licenciam et per presentes concedimus per auctoritate predicti capituli generali... : « ... nous avons concédé à l'abbé, à sa communauté et à leurs successeurs la licence de vendre la coupe de la dite forêt au mieux qu'ils pourront, et par la présente nous leur concédons par l'autorité du dit chapitre général...».

20. Jean-Berthold MAHN, op. cit., p. 207. «Dès 1182, il fut arrêté que les abbés endettés qui continueraient à dépense devraient en demander pardon au chapitre ".

21. Dans les deux mentions hors-teneur, il est : ...Autissiodorensis diocesis clericus, auctoritate apostolica publicus notarius... La série E des A.D.Yonne ne contient aucun registre notarial pour la période antérieure à 1481. Voir A.D. Yonne, E 368-510.

22. Christine BARNEL, « Une ville provençale et sa campagne au XIV ${ }^{\mathrm{e}}$ siècle : Toulon, les notaires et leur clientèle ", in La ville au Moyen Âge, 1, Ville et espace, Noël Coulet et Olivier Guyotjeannin (dir.), Paris, 1998, p. 233-245 : l'auteur parle des notaires et de leur clientèle, sans jamais évoquer les sommes versées . Gustave DUPONT-FERRIER, Les officiers royaux des bailliages et sénéchaussées et les institutions monarchiques locales en France à la fin du Moyen Âge, Paris, 1902, [reprint Genève, 1974], p. 227 : « Les émoluments des notaires étaient payés d'après un tarif précis ». Marie-Thérèse LORCIN, « Le notaire dans le milieu rural au Moyen Age ", in Le Notariat dans la société : histoire et avenir ; Le Gnomon, Revue internationale d'histoire du notariat, $n^{\circ} 48$, mars 1986 (Actes du colloque de Paris, 4 février ), 1986, p. 61-69 ; ID, « Les clercs notaires dans les testaments foréziens des XIV et XV siècles », in Le clerc au Moyen Âge, Senefiance, 37, 1995, p. 387-388 : « La tonsure n'empêche nullement le clerc d'être marié, pas plus qu'elle ne lui interdit de posséder des biens, ni de faire payer ses services ». Odile REDON, « Les notaires dans le paysage culturel toscan des XIII ${ }^{\mathrm{e}}-\mathrm{XV}^{\mathrm{e}}$ siècles, scribes, traducteurs, auteurs ", in Hommage à Jacqueline Brunet, Annales littéraires de l'Université de Franche-Comté, Marcella Diaz-Rozotto (dir.), 1997, p. 215 : «... le prix des actes ne dépendait pas du prestige des praticiens mais était réglé par le statut de l'Art ».

23. Le rapport mesure $38,5 \mathrm{~cm}$ de haut pour $38 \mathrm{~cm}$ de large.

24. Marie-Thérèse LORCIN, «Les clercs notaires dans les testaments foréziens des XIV et $\mathrm{XV}^{\mathrm{e}}$ siècles ", op. cit., p. 389. Odile REDON, op. cit., p. 213 : « La profession du notaire consiste essentiellement à rédiger des contrats, sous deux formes affirmées au XIII ${ }^{\mathrm{e}}$ siècle qui leur confèrent une égale valeur probatoire : la minute, forme abrégée du 
contrat, écrite dans un cahier [...] qui appartient au notaire et reste toujours par-devers lui, puis après sa mort chez ses héritiers ou son successeur [...], et l'acte original écrit in extenso sur parchemin et remis aux contractants sur leur demande... ». A.D. Yonne $\mathrm{H}$ 1570 , acte de $1370: . .$. ipsa omnia in hanc publicam formam redegi... .

25. TOni DIEDERICH, « Ad majorem cautelam. Zur Kumulation von Beglaubigungsmitteln in einer Urkunde des Kölner Domkapitels von 1480 », Archiv für Diplomatik, 52 (2006), p. 189-190 : les souscriptions des deux notaires de l'acte du chapitre de Cologne de 1480 ont à peu près le même contenu. Odile REDON, op. cit., p. 216 et 219-220.

26. Confirmation du notaire Guillaume dans l'acte de 1369 : Et ego Guillemus Grandi de Lano Autissiodorensis diocesis clericus auctoritate apostolica publicus notarius, premissis omnibus et singulis dum sit ut premittatur dicta die quinta mensis septembris in predicto parlamento per dictos religiosos agentur, dicentur, tractarentur et fierent una cum predictis religiosis et prenominatis testibus presens fui eaque sic trattari, concordari et fieri vidi at inde presens publicum instrumentum manu mea propria confirmo et signo meo solito me etiam hic manu predicta subscribendo signari requisitus super hoc per dictos religiosos et et rogatus in testimonio premissorum. Confirmation du notaire Guillaume dans le rapport de 1370 : Et ego Guillelmus Grandi de Lano Autisiodorensis diocesis clericus auctoritate apostolica publicus notarius, premissis omnibus et singulis dum sit ut premittatur per dictos domnos commissarios in dicto capitulo monasterii Regniaci, agentur, dicentur et fierent, una cum ipsis dictis et aliis religiosis supranominatis presens fui eaque sic dicti et fieri vidi et audivi ac ipsa omnia in hanc publicam formam redegi presentesque litteras seu presens publicum instrumentum manu mea propria confeor et signo meo solito me etiam hec manu predicta subtulendo signavi requisitus super hoc et rogatus in testimonio premissorum.

27. Paris, BnF, ms. lat. 17725, acte 46, fol. 23v : Et ego Guillaume de Lano Autissiodorensis diocesis clericus, auctoritate apostolica publicus notarius, permissis omnibus et singulis dum sit ut permittitur, agerentur, dicerent et fierent una cum predictis testibus presens fui, eaque sic dici et fieri vidi et audivi ac ipsa omnia in hanc publicam formam redigendo, presens publicum instrumentum exinde consertum quod aliis negociis occupatus per alium scribi feci, signo meo solito me hic manu mea propria subscribendo signavi, requisitus et rogatus, rasuras et intelineares factas in hiis [...] sexagesimo nec absentis contraris de quibus michi legitime constat hic expresse approband[...] in testimonio premissorum.

28. Toni DIEDERICH, op. cit., p. 175 : « Die Kriterien eines vollgültigen Notariartsintrumentes sind im vorliegenden Falle erfüllt, gaben doch « in Deutschland nur Unterschrift und Signet zusammen der Notarurkunde den Charakter einer öffentlichen Urkunde ». An der Ausfertigung der Kölner Wahlinstrumentes wirken zwei Notare durch ihre eigenhändigen Unterschrift und Signete mit ».

29. Thomas VOGTHERR, « Siegelrecht, Siegelmißbrauch und Siegelfälschung bei den Zisterziensern ", Archiv für Diplomatik, 45 (1999), p. 64-65; Chrysogonus WADDELL, Twelfthcentury statutes from the cistercian general chapter, Brecht, Cîteaux, Commentarii cistercienses, 2000, 1200, statut 14, p. 458 : Quia in sigillis Ordinis quaedam discordia invenitur et quaedam exinde nascitur novitas, praecipitur quatenus amodo in sigillis nulla discrepantia habeatur, sed sola simplici effigie cum baculo, vel sine effigie cum manu et baculo consignetur et annotetur. Le sceau de l'abbé de Reigny est en navette. Il représente l'abbé en pied, avec une crosse, un livre et autour une devise très simple : sigillum abbatis Regniacensis. C'est le cas du sceau de l'abbé Elie en 1200. Plus de trois siècles plus tard, en 1538, la matrice du sceau de Jacques de la Clayette reprend le même modèle, en l'adaptant toutefois au goût du jour. 
30. Toni DIEDERICH, op. cit., p. 175. Marie-Thérèse LORCIN, « Les clercs notaires dans les testaments foréziens des XIV et XV X $^{\mathrm{e}}$ siècles », op. cit., 37 (1995), p. 393 : « Le notaire des pays de droit écrit peut [...] authentifier les actes par la seule apposition de son seing manuel ». Odile REDON, op. cit., « ... le travail [des notaires] était de produire des écrits qui faisaient foi... ». W. SCHмIDT-TномÉ, « Vom Notarsignet zum Notarsiegel. Ein Beitrag zur Geschichte des Notariats und der Notarurkunde », Deutsche Notar-Zeitschrift, 8, 1964, p. 464.

31. Paris, BnF, ms. lat. 17725, acte 41 fol. 18-18v : « Charles, par la grace de Dieu, roy de France. Aus baillis de Sens et Daucerre ou a son lieutenant, salut. Nous biens amés les religieux abbe et convent de leglise de nostre Dame de Reigny de lordre de Cisteaux, nous ont fait expose en complaignant que comme lesdits religieux aient contribue ala closture et fortificacion et emparement de nostre forteresse de Vermenton qui est plus prochain lieu fort de leur eglise ou quel il ont fait faire et edifier ung hostel ou maison a leurs despens, pour mectre et retraire eulz et leurs biens, familiers et serviteurs a sauvete, et toutes foiz quil leur a pleu ou temps passe ont eu retrait et refuge en nostre dicte forteresse, paisiblement et sanz empeschement aucun. Neansmoins, Jehan de Lesvres, habitant de la ville de Vermenton soy disant capitaine de ladite forteresse assise en ladite ville ou autres ses lieuxtenants portiers ou commis ala garde dicelle de la volente et commendement dudit Jehan de Lesvres en haine daucuns plais et proces que lesdits religieux pour certaines justes causes ala conservacion du droit de ladite eglise ont et soustiennent touts lesdits habitants de Vermenton ou autrement de leur volente desraisonnable a tort sanz cause et contre raison, ont nagueres refusé et denié ausdits religieux ou a leurs gens, familiers ou serviteurs l'entree de la porte de nostredicte forteresse ». Original conservé aux A.D. Yonne, H 1564.

\section{INDEX}

Mots-clés : abbaye cistercienne, Guerre de Cent Ans, charte bourguignonne Index géographique : France/Reigny 